\title{
UM PAINEL SOBRE AS OBRAS DE JACK KEROUAC TRADUZIDAS NO BRASIL NA DÉCADA DE 1980*
}

\section{Marco Antônio Margarido Costa**}

RESUMO: O objetivo do presente texto é analisar uma seleta da fortuna critica de obras de Jack Kerouac (1922-1969) traduzidas no Brasil, na década de 1980. A saber: On the road: pé na estrada, Os subterrâneos, Viajante solitário, O livro dos sonhos e Big Sur. Resultado da pesquisa em fontes primárias, esta análise faz parte da nossa dissertação de mestrado, que, além de fornecer e analisar essa seleta, buscou mostrar o primeiro momento da recepção da obra de Jack Kerouac no Brasil, reconstituir a polêmica gerada acerca das publicações dos textos beat no Brasil e revelar alguns escritores brasileiros que foram influenciados pelos artistas da beat generation, movimento literário norte-americano ocorrido nos anos 1950, ao qual Jack Kerouac pertenceu. O presente artigo mostra, a partir de algumas críticas - ou da relação entre elas -, como Kerouac foi visto no Brasil via tradução, fornecendo assim um painel sobre sua recepção, avaliando o tratamento que lhe foi dado e reconstituindo uma visão do espaço que ocupou na imprensa brasileira.

UNITERMOS: Jack Kerouac; Geração beat, Fortuna crítica; intertextualidade; tradução; resenha.

ABSTRACT: The objective of this text is to analyze a collection of criticism of Jack Kerouac's works (1922-1969) which came to be

* Este artigo é parte da Dissertação de Mestrado intitulada Um estudo sobre a contribuição da crítica para a percepção das obras de Jack Kerouac traduzidas no Brasil, defendida no Programa de Pós-Graduação da Faculdade de Filosofia, Letras e Ciências Humanas da Universidade de São Paulo, área de concentração: Língua Inglesa e Literaturas Ingle sa e Norte-Americana, sob a orientação da $\operatorname{Prof}^{a} \operatorname{Dr}^{a}$ Regina Helena Elias Alfarano.

* Doutorando em Estudos Lingüísticos e Literários em Inglês da Faculdade de Filosofia, Letras e Ciências Humanas da Universidade de São Paulo. 
translated and published in Brazil in the 1980's as: On the road: pé na estrada (On the road), Os subterrâneos (The subterraneans), Viajante solitário (Lonesome traveler), O livro dos sonhos (Book of dreams) and Big Sur (Big Sur). Being the result of a research with primary information sources, this analysis is a part of our Master's Dissertation which, besides supplying and analyzing this collection, depicts the initial moment when Kerouac's works became known in Brazil, reproduces the debate when beat works came to be published in Brazil and reveals some Brazilian writers who were influenced by the beat generation, literary movement of the 1950's in America, which Jack Kerouac used to belong to. Based on some reviews, or the relation between them, this article shows how Kerouac was seen in Brazil via translation, providing, therefore, an overview of his reception, evaluating the treatment that was given to him and reconstructing a vision of the space he occupied in the Brazilian press.

KEYWORDS: Jack Kerouac; Beat generation; selection of criticism; intertextuality; translation; review.

\section{Introdução}

Nas Letras, quando falamos do conceito de "intertextualidade", fazemos referência à construção de textos se nutrindo de fontes diversas. Quais foram os elementos usados que deram origem a um novo texto? Analisar o modo como um texto se insere em outro, como esse encadeamento cria novos textos e como diversas vozes se mesclam e constroem um novo texto é a idéia que norteia este trabalho. A observação de como os artigos se relacionam, se complementam, se contrapõem ou se incorporam, faz com que a obra de Jack Kerouac se complemente e viva, de maneira dialógica, por meio da crítica. ${ }^{1}$

1 A seleta da fortuna crítica incluída na Dissertação de Mestrado congrega 36 resenhas críticas específicas sobre as obras traduzidas no Brasil. A Editora Brasiliense publicou, em 1984, On the road: pé na estrada, e Os subterrâneos; em 1985, Viajante solitário e Big Sur. Também em 1985, pela Editora L\&PM, O livro dos sonhos. Como fonte de pesquisa, foram selecio-

TRADTERM, 12, 2006, p. 247-267 
Uma das reflexões desenvolvidas em nossa dissertação de mestrado salientou que foi possivel recuperar duas vertentes críticas, no momento das primeiras publicações das obras de Kerouac no Brasil. A primeira, como jogada de marketing editorial, com a intenção de criar um modismo ou revival; a segunda, buscando um interesse especificamente literário.

Ao analisarmos as críticas específicas sobre a tradução de On the road: pé na estrada, ${ }^{2}$ publicada no Brasil em fevereiro de 1984, notamos, entretanto, que não há grande destaque sobre essas vertentes. A maioria dos artigos aborda aspectos comportamentais ou biográficos do autor, constituindo-se dessa forma reproduções que informam aos leitores características ora de Kerouac, ora do movimento beat. ${ }^{3}$ Poucos se arriscam a desenvolver uma análise minuciosa de aspectos realmente literários, como linguagem, elaboração narrativa ou recursos prosódicos. ${ }^{4}$ Perrone-Moisés (1993: 58) afirma que: "Em principio, a crítica sempre foi intertextual." Sobre dialogismo e intertextualidade, explica que "a crítica se depara, mais do que nunca, com o problema das relações entre diferentes discursos, entre diferentes textos."

nados o arquivo da Editora Brasiliense, por ser responsável pelo maior número das publicações no Brasil, os arquivos da Editora Abril Cultural e dos jornais Folha de S. Paulo, O Estado de S. Paulo, O Globo e Jornal do Brasil.

2 Eduardo Bueno e Antonio Bivar traduziram On the road, cujo título original foi mantido no Brasil, acrescido do subtítulo pé na estrada. Paulo Henriques Britto traduziu Os subterrâneos (The subterraneans) e Big Sur (título original mantido). A tradução de Viajante solitário (Lonesome traveler) foi de Eduardo Bueno, e a de O livro dos sonhos (Book of dreams), de Milton Persson.

3 O movimento beat nos Estados Unidos esteve muito ligado a uma idéia de inconformismo, de rebeldia contra o convencionalismo e a moralidade retrógrada que tomavam conta da sociedade norte-americana nos anos que se seguiram ao fim da Segunda Guerra Mundial.

4 Kerouac se apresentou como inventor de uma prosa "espontânea", repleta de sonoridade, gírias e coloquialismo. Suas frases deixavam de lado a ordem natural da sintaxe, com imensos parágrafos indo e voltando no tempo, em um misto de relato e reflexão. Sua linguagem espontânea, chamada até mesmo de jornalística, somada ao caráter visionário, algo meio místico presente em sua ficção dá a impressão de estarmos diante de relatos de diários - gênero de fronteira interdisciplinar. 
Antes de realizarmos essa análise proposta, partindo do levantamento suscitado pela ensaísta, evocamos novamente a escritora, que afirma que:

Toda crítica deve apoiar-se numa base teórica, em pressupostos, sob pena de ficar exposta a contradições internas ou de nunca ultrapassar a descrição do objeto. Ora, a descrição do objeto é, ao nosso ver, um primeiro passo necessário mas não suficiente. (Perrone-Moisés, 1973: 160)

Observamos que, ao apresentar a obra, a critica deteve-se, por meio de relações intertextuais, a explorar sempre os mesmos aspectos, estando submetida, portanto, apenas a esse critério básico elucidado por essa autora. Citamos o exemplo da tradução, a dificil tarefa do tradutor de encontrar palavras em português que apresentem a mesma sonoridade do inglês foi pouco desenvolvida ou praticamente esquecida.

A fim de estabelecermos alguns limites para visualizarmos a intertextualidade presente nas resenhas, passaremos a utilizar as designações que Fiorin (1999) distingue como processos de intertextualidade: a citação, a alusão e a estilização. O primeiro processo - a citação - ocorre quando a referência a um outro texto se faz de maneira explícita, com palavras que confirmam ou alteram o sentido do texto citado.

O segundo processo intertextual apresentado - a alusão ocorre quando há uma reprodução de construções sintáticas. Não há citações explícitas, como no processo anterior, mas observa-se a construção do texto por meio de temas semelhantes.

Finalmente, com a estilização, a relação com outro texto se faz pela reprodução de seu estilo, que podemos observar ora pelo conteúdo, ora pela forma apresentada.

\section{Análise das criticas de On the road: pé na estrada}

Em "O anjo decaído", primeira crítica sobre a tradução de On the road de que dispomos, Gonzalez (1984) afirma que Kerouac "tentou a mais impossivel das literaturas - a que não deixa nenhum espaço de separação entre literatura e vida." Comprovan- 
do a reflexão de Calinescu (1993: 42) sobre a dificuldade de se ler um texto "inocentemente", ou seja, sem nenhuma influência "externa", após a leitura dessa resenha, o leitor brasileiro que ainda não conhecia o texto de Kerouac poderia fazer uma leitura tendenciosa, buscando encontrar em On the road: pé na estrada aspectos meramente biográficos de seu autor. O comentário de que "o tema de On the road é assim a própria literatura - e secundariamente o jazz, o amor, as viagens ou as festas" aniquila qualquer possibilidade de interpretação que o leitor pudesse vir a ter. Conforme defendeu Perrone-Moisés (1973: 161), a crítica não deve acreditar "numa verdade da obra mas em sua pluralidade." Além de não esclarecer essa relação entre a obra em questão e a literatura, Gonzalez, contrariando Perrone-Moisés, resume o tema do romance apenas a jazz, amor, viagens ou festas. Quanto ao texto de Kerouac, declara que o atraso da publicação de On the road: pé na estrada no Brasil propiciou ao leitor "comprovar o funcionamento do texto fora daquela 'eternidade' que Kerouac procurou para ele nos anos 50."

Encontramos reflexos desses elementos no artigo "No ritmo do coração". ${ }^{5}$ Nele, o crítico não enquadra On the road no "reino da ficção"; no entanto, valoriza "as lições de rebeldia e inconformismo" apresentadas na obra. Essas características fazem com que a obra permaneça "atual". Entendemos que a análise de Gonzalez (op. cit.), que sugere "comprovar o funcionamento" da obra desconectada do contexto em que ela foi escrita, significa dizer que essa mesma obra é "atual”, ou seja, que apresenta temas que o leitor pode reconhecer como "recentes" ou que estão sempre presentes no seu cotidiano.

Para Paiva (1984), On the road apresenta uma "consciência beat", que faz com que a obra seja "passado, presente e futuro." Ao ver essa ausência de limite de tempo, o crítico faz ecoar em seu artigo citações das duas leituras anteriores que também abordaram essa característica "atemporal" do texto de Kerouac. $\mathrm{O}$ articulista refere-se também ao estilo de Jack Kerouac, sem acrescentar interpretação mais significativa.

5 Esclarecemos que, quando apenas o título for mencionado, trata-se de artigo sem autoria. 
Ao iniciarmos a leitura do texto de Querino Neto (1984), observamos a sugestão do crítico de que "estar na estrada" significaria implicitamente não ter saído dela, ou - para usar uma palavra já sugerida pela análise das três críticas anteriores - ser "atual". Isso se comprova pelo questionamento explícito que o autor faz ao desenvolver seu artigo: "Mas por que ele [Kerouac] é ainda tão atual?". Sem apresentar respostas, o crítico recorre novamente à citação ao incluir um trecho de Leaves of grass, de Walt Whitman, e, logo em seguida, um trecho de On the road. Por meio das referências às obras de Whitman e Kerouac, respectivamente, observamos a associação que o crítico faz com textos previamente existentes e conhecidos, dando origem à resenha em questão - aspecto que justifica o caráter intertextual que temos tentado demonstrar. Ao descrever o significado de literatura para escritores como Walt Whitman, Ernest Hemingway, Jack London, Norman Mailer e Henry Miller, vemos a comparação entre Whitman e Kerouac, fazendo com que o escritor de On the road esteja incluido entre nomes importantes da literatura norte-americana.

Pinto (1984), autor do artigo "Pé na estrada", inicia sua interpretação salientando exatamente essa característica citada anteriormente - a "atualidade" do texto de Kerouac e a falta que fazia aos leitores brasileiros. Observamos a construção desse artigo com aforismos que demandam maior detalhamento. No entanto, servimo-nos dele para ilustrar o processo de estilização que ocorre ao fazer comparações entre Jack Kerouac e nomes importantes da literatura norte-americana. Vemos que em ambos artigos o objetivo é incluir Jack Kerouac entre nomes significativos da literatura norte-americana. No entanto, a maneira como cada um o faz é diferente. Em artigo bastante conciso, o crítico, sem explicar porque o texto de Kerouac é "atual", passa a classificá-lo como "moderno", sendo seu lançamento no Brasil "oportuno". Aponta Kerouac como "legítimo descendente de Walt Whitman e uma espécie de êmulo dos anos 1950 de Ernest Hemingway", realizando literatura "comprometida com o homem e seus desejos." Acreditamos que essas afirmações requerem maior questionamento. O que era ser "moderno" à época da publicação de On the road no Brasil? Apesar do enaltecimento apresentado, 
ficamos com a impressão de estarmos diante de uma "obra-prima" sem saber exatamente quais critérios teriam sido usados para assim a definir.

Destacamos outros exemplos de "citação" nos artigos que tratam basicamente de informações biográficas sobre Jack Kerouac. Em dois deles, publicados em jornais, ${ }^{6}$ observamos que ambos destacam depoimentos sobre a vida de Jack Kerouac relatados nos próprios livros do autor. O segundo estende-se um pouco mais, incluindo comentários do jornalista Pepe Escobar e um trecho de um ensaio do poeta Leonardo Fróes.

Vemos no artigo de Ciccacio (1984) outro exemplo de construção intertextual. Jack Kerouac elaborou 30 itens, que denominou "Credo e técnica da prosa moderna, segundo os beatniks". ${ }^{7}$ Nele, discorreu sobre os conceitos que julgava refletir o espírito de um escritor beat. Vemos, nesse artigo, alguns desses itens citados, que funcionam como ponto de partida para análise da autora, tornando a construção desse texto uma "colagem" de opiniões. A autora recorre à opinião de Cláudio Willer, poeta e tradutor que defende a literariedade de Kerouac. Destaca o fato de Willer ser contrário à posição daqueles que viram a literatura beat no Brasil apenas como "modismo" e relaciona esse ponto de vista com a do também tradutor da obra, Antonio Bivar.

Com destaque ainda dado à vida de Jack Kerouac, a resenha de Menezes (1984) apresenta On the road como a "experiência pessoal de Kerouac como estradeiro, mostrada de maneira ficcional." Menezes limita-se a informar ao leitor sobre persona-

\footnotetext{
6 Artigos sem autoria, cujos títulos são: "On the road: o relato de viagem da geração beat" (Pioneiro) e "On the road, de Kerouac: a Bíblia beat chega ao Brasil” (Correio da Bahia).

7 A palavra beatnik, que foi usada para designar qualquer boêmio extravagante, parece ter sido inventada por um jornalista do San Francisco Chronicle, Herb Caen. Nik é um sufixo iídiche que indica uma coleção, um grupo. O Sputinik russo acabara de ser lançado ao espaço, a maré de rebeldia ganhara espaços na imprensa e On the road era um sucesso de venda. Para Kerouac, os beatniks eram poetas, pintores, escritores e intelectuais da cultura não-oficial que desprezavam e contestavam o American way of life e que, para protestar contra a repressão e o controle da cultura e da vida sexual, deixavam crescer a barba e o cabelo, experimentavam drogas e viajavam sem destino pelo pais, impregnados de jazz, blues e de um sentimento de solidariedade em busca de respostas para suas angústias existenciais.
} 
gens da obra, relacionando-as com pessoas da vida real, amigos de Kerouac como Neal Cassady (Dean Moriarty em On the road). Compara também as viagens descritas na obra com as dos antigos colonizadores norte-americanos em busca de fortuna ou "simplesmente fugindo de si próprios ou de outros."

Em outro artigo, ao fazer um convite à leitura de On the road, Abreu (1984) ${ }^{8}$ aborda também o aspecto da viagem na obra, de maneira metafórica. Classifica as viagens de carona descritas no romance como "procuras existenciais das personagens". Notamos esse comentário aproximar-se da leitura anterior de Menezes, onde o crítico compara as viagens relatadas em On the road com a dos colonizadores, atribuindo às viagens uma interpretação mais sociológica. Abreu também retoma, em seu artigo, a informação de que Kerouac tenta aproximar vida e literatura, já vista em "O anjo decaído", de Gonzalez, julgando apresentar essa aproximação resultado "saborosíssimo".

Em "O moderno clássico da beat generation", Junqueira (1984) descreve a viagem em On the road como uma "busca das raízes da vida". Diferentemente dos artigos anteriores que analisaram esse mesmo tópico, neste, o autor ressalta que há "duas viagens" no livro: "uma, epidérmica e linear" e outra, "subterrânea e abissal". Com essa interpretação, acreditamos que o autor acrescenta novo sentido à "viagem" empreendida pelos protagonistas de On the road, e que pode corroborar o desenvolvimento de um futuro estudo sobre a obra de Jack Kerouac. Após lermos essas resenhas onde o aspecto da viagem empreendida pelo protagonista é abordado, observamos a ocorrência do intertexto pela "estilização". Cada crítico, a seu modo, propõe uma interpretação diferente, provocando uma permuta entre os textos cujo tema é único - viagem.

Observamos no artigo publicado no jornal Zero Hora, de autoria de Ucha (1984), o tradutor Eduardo Bueno ser apontado como pessoa "melhor indicada" para traduzir On the road. A carreira jornalística de Bueno é relatada, assim como seu interesse por Jack Kerouac e o despertar do desejo em traduzir a obra após ter viajado pelos mesmos lugares descritos em On the road.

8 Artigo sine nomine pertencente ao arquivo da Editora Brasiliense. 
Conforme o artigo, a experiência de vida do jornalista Bueno, seu estilo e capacidade de absorver o espírito da obra colaboraram para que a mesma fosse traduzida no Brasil.

Comentando a tradução de On the road, Assunção (1984) fornece resumidamente um painel, retomando ou "colando" comentários de críticas anteriores. Nele, detalha o motivo que levou Eduardo Bueno a traduzir a obra e as dificuldades encontradas em adaptar o texto original ao português. Retoma a visão dos jornalistas que viram a literatura beat no Brasil como um retorno aos anos 1950 e critica o mercado editorial brasileiro.

Conforme pudemos observar, apesar de a maioria das resenhas conter informações biográficas, elas vêm acompanhadas de um lamento que se faz presente, ora no título, ora no próprio corpo da crítica - o "atraso" da tradução. Notamos também que, apesar da repetição exaustiva de certos elementos (por exemplo, viagem, aventura), um aspecto que torna a abordagem bastante periférica, On the road foi recebida com empolgação. Destacamos alguns títulos de artigos que, além de ilustrar essa empolgação, também demonstram sua intertextualidade ao recorrer ao processo da "alusão".

Notamos a ligação da palavra "decaído", apresentada no primeiro artigo da análise, com a própria definição da palavra beat. ${ }^{9}$ Entendemos que atribuir o adjetivo "decaído" a alguém significa qualificá-lo de "enfraquecido", "arruinado". Ao resgatarmos o sentido que foi atribuído a beat, observamos a palavra "decaído" remeter ao significado de alguém que está "cansado" ou "derrotado". Essa associação ilustra a relação intertextual

\footnotetext{
9 Essa palavra foi usada inicialmente por Herbert E. Huncke, amigo de William Burroughs, escritor que também fez parte do núcleo inicial da geração beat. Huncke usava esse termo no sentido de "estou "exausto" (I'm beat), cansado, derrotado, vencido, arrebentado, "na pior". Além de significar o verbo "bater", beat também é um termo musical: designa "batida", ritmo, a "pulsação de um tema ou de uma improvisação jazzística". Para Kerouac, cuja obra é marcada por uma forma toda especial de misticismo, beat apresenta também outro sentido: uma abreviatura de beatitude (beatific), a pretendida felicidade suprema dos misticos. Beat pode significar então esse jogo entre beato e religioso, que Kerouac faz, englobando todos esses significados. Beat é batida (do coração), é batida de jazz, pulsação musical e também alguém que está exausto, caído, derrotado.
} 
que se faz substituindo alguns elementos (palavras) por outros, sem perder a relação de sentidos, a possibilidade de interpretação de significados dentro de um elemento sugerido.

Destacamos outro exemplo de "alusão" presente no artigo cujo título "No ritmo do coração" as palavras "ritmo" e "coração" estabelecem uma margem possível de conexões. Vemos as possibilidades de relação dessas palavras também com o sentido atribuído à palavra beat, que na música designa "batida, pulsação" e por extensão, "ritmo". Para a palavra "coração" também podemos atribuir ampla interpretação, ao relacionarmos com "pulsação" e também "batida", que por conseqüência desenvolve certo ritmo ao fazê-lo.

Quanto aos demais títulos dessa série, observamos que, em sua maioria, o próprio título da obra é citado para nomear o artigo. Tal transposição ressalta o uso do intertexto como origem da crítica e, em alguns casos, como dissemos, o ressentimento pelo "atraso" da tradução da obra. Na seqüência em que as resenhas são apresentadas, salientamos os títulos: "Quase 30 anos depois, enfim em português, On the road" (Menezes, 1984), "Com 27 anos de atraso, chega ao Brasil o credo do movimento beat" (Ciccacio, 1984) e "Na estrada, quase 30 anos depois" (Querino Neto, 1984). Os demais títulos, com poucas exceções, apresentam o título da obra ora na língua original em que foi escrita, ora em português.

Vale a pena nos determos um momento no importante trabalho do tradutor. Poucos artigos abordam o aspecto da linguagem em On the road. Os que o fazem descrevem en passant características já mencionadas sobre o estilo de Kerouac, como direto, rápido e capaz de romper com as normas da linguagem. Alguns ainda classificam o livro como "clássico" e a narrativa de Kerouac como pertencente à poesia. Vemos o leitor ser surpreendido com informações que julgamos necessitar de maior elaboração, o que não ocorre com a maioria das resenhas. Vejamos alguns artigos que discorrem sobre o aspecto da tradução.

No artigo "O grande clássico da geração Beat", ${ }^{10}$ a tradução de On the road é apontada como "boa e atualizada". Ao clas-

10 Título atribuído pelo organizador. 
sificar a linguagem apresentada como "vibrante, nervosa, apaixonante e plena em adjetivos", o autor da resenha parece chegar ao limite do que poderia ser uma interpretação menos periférica da obra de Kerouac. Lastimamos o fato de o autor não discorrer sobre os motivos pelos quais considera a tradução "atualizada". Acreditamos que caberia explicar a contextualização da obra, ou seja, discorrer sobre a maneira pela qual os tradutores reproduziram a linguagem dos anos 1950, quais palavras foram usadas em português com os mesmos valores sonoros do inglês - características que tornariam a análise mais consistente.

O artigo de Ismael (1984) elogia a tradução da obra, asseverando que os leitores conseguem se "esquecer" de que o texto original foi escrito em língua estrangeira. Afirma também que considera essa característica como a mais importante de uma boa tradução. Nesse artigo, como no anterior, observamos, para o leitor não-versado nos problemas da linguagem, a ausência de informação, deixando-o sem noção do que possa ser uma "boa tradução".

Destaque à tradução, com comentários que provocam mais reflexão sobre a linguagem, foi despertado em "O moderno clássico da beat generation”. Nesse artigo, Junqueira (op. cit.) classifica a tradução como "excepcional". Sua interpretação baseia-se no interesse empreendido pelos tradutores em preservar o "ritmo vertiginoso" que o original apresenta, procurando palavras equivalentes em português que pudessem se aproximar das gírias e expressões idiomáticas que permeiam toda a obra. Infelizmente, o crítico não apresenta exemplos que possam ilustrar esse complexo trabalho, não transmitindo, portanto, a exata dimensão dessa tarefa ao leitor sem domínio do inglês.

Apesar da ausência desses exemplos, destacamos que os três artigos possuem como tema a qualidade da tradução. Por maneiras diferentes, os críticos tentam transmitir uma única mensagem - a de que a obra original foi bem traduzida. A estilização ocorre nesses exemplos onde temos como objeto da análise a tradução. No artigo "O grande clássico da geração Beat", o crítico refere-se à tradução como "atualizada". Ismael (op. cit.) aponta que os leitores conseguem "se esquecer" de que o texto original não foi escrito em português. Finalmente, Junqueira (op. 
cit.) ressalta que os tradutores conseguem preservar o "ritmo" do texto original. Observamos existir estreita relação entre essas afirmações. Há um intercâmbio de informações que são absorvidas e transmitidas ao leitor de maneiras distintas. Retomamos que reconhecer a atualidade da tradução de um texto escrito originalmente trinta anos atrás é destacar que o tradutor desempenhou papel vital para tal empreendimento. Por meio de seu trabalho de selecionar, analisar e comparar palavras em português que se aproximassem dos valores sonoros e semânticos do texto original, mantendo, no caso de On the road, o mesmo "ritmo" do original, faz conseqüentemente com que o leitor esqueça em que língua o texto foi originalmente escrito. Observamos "estilização" nesses exemplos como transformação no plano do conteúdo das críticas.

\section{Análise das criticas de Os subterrâneos}

A tradução de The subterraneans (Os subterrâneos) foi publicada no Brasil em agosto de 1984. Os artigos sobre essa segunda obra de Kerouac traduzida no Brasil contêm elogios quanto à elaboração do texto; no entanto, nos deparamos com classificações que não acrescentam ao leitor informações mais consistentes. Conforme mencionamos, encontramos alguns artigos que enquadraram a narrativa de Kerouac no gênero poético. A leitura de duas resenhas nos remete a essa referência. Ferraz (1984) começa seu artigo citando a apresentação de Willer (1984) na obra traduzida. Ferraz acrescenta dados biográficos do autor, cita escritores que o teriam influenciado e salienta que, quanto à narrativa de Kerouac, podemos encontrar "passagens poéticas" em Os subterrâneos. Observamos que, a exemplo dos artigos que relacionaram a narrativa de Kerouac com a poesia, esse crítico não pontua quais são as referências poéticas presentes na prosa.

Destacamos o artigo de Rocha (1984), que também faz referência à poesia. Segundo esse autor, o estilo da narrativa de Kerouac, considerado sem "autocensura", faz com que ele mostre influências do escritor James Joyce - fato que, para o rese- 
nhista, se revela quando há citação de Finnegans Wake pela personagem principal de Os subterrâneos. Após essa tentativa de buscar em Kerouac características de Joyce, o crítico menciona, então, um trecho do romance de Kerouac que viu tratarse de uma declaração sobre o "ato de amar", classificando como "momento poético" do romance.

Parece-nos que a apresentação de Willer ressoa em alguns dos artigos que relacionamos, ora explicitamente, como vimos no primeiro artigo analisado, ora implicitamente. Willer (op. cit.: 9) descreve que Os subterrâneos é "a obra especialmente representativa da 'prosódia bop', do estilo que Kerouac criou." Vemos, em outro artigo, intitulado "O melhor da literatura beat", comentários referentes ao estilo de Jack Kerouac, cujo livro é apresentado como sendo "uma narrativa mais tipicamente beat", e que Os subterrâneos seria o "mais espontâneo" dos textos do escritor. Observamos a estreita ligação com a apresentação feita por Willer.

Biondo (1984), em artigo para o jornal O Globo, nota a qualidade do texto de Kerouac, destacando o uso que o autor faz da linguagem, atribuindo-lhe a responsabilidade pelo "resgate da fala da primeira pessoa na criação literária." Salientamos que Willer (op. cit.: 10) também ressaltou como uma das grandes contribuições de Kerouac "a recuperação do sujeito, a fala do narrador e a primeira pessoa na criação literária”. Biondo (op. cit.) classifica, também, o romance como "documento de época"; no entanto, questiona se a temática de Kerouac resistiria aos anos 1980 .

Parte desse artigo de Biondo está incorporada à resenha "A prosa do futuro em Os subterrâneos". Além de citar o questionamento daquela autora, esse artigo traz comentários a respeito do estilo de Kerouac e relata a polêmica ocorrida quanto ao valor literário do escritor, situando o trabalho de Kerouac dentro da "literatura contemporânea". Depreende-se que fazer parte da literatura contemporânea, para o autor do artigo em questão, está diretamente ligado à receptividade do mercado, independentemente da qualidade do texto, pois o artigo traz referências à quantidade de traduções, ensaios, artigos e resenhas publicadas em várias partes do mundo sobre Jack Kerouac. 
Sublinhamos que, diferentemente dos artigos analisados na série anterior, nesta, os textos selecionados não abordam a questão da tradução. A dificuldade do tradutor da obra para reproduzir a sonoridade das palavras, refletindo o "estilo espontâneo" de Kerouac, tão marcadamente citado em críticas anteriores, não é levado em conta. O comentário que mais se aproxima dessa interpretação foi sugerido por Fróes (1984). Salientamos como exemplo de intertexto nesse artigo o fato de esse autor recorrer a uma definição de Os subterrâneos, que, mencionada por Ann Charters, biógrafa de Kerouac, inclui em sua resenha. Cita também em seu artigo, como aspecto marcante no livro, o fato de poder ser "declamado". Essa sugestão reforça o aspecto da oralidade no texto de Kerouac. No entanto, o artigo não apresenta exemplos de como tais características são encontradas.

Destacamos também a intertextualidade presente em alguns títulos dos artigos sobre Os subterrâneos. Conforme mencionamos, a construção textual dessa obra mereceu elogios por parte da crítica, fato que se revela através de alguns títulos como "Nas livrarias, os textos que saem no ritmo dos corações"; "Na alma dos personagens e do cenário, um documento de época" (Biondo, 1984) e "O melhor da literatura beat". Chamamos a atenção novamente para o fato de esse primeiro título relacionado remeter a sugestões que citamos na série anterior, ao usar as palavras "ritmo" e "corações".

Somos levados a refletir sobre "certas condições" que a ensaísta Perrone-Moisés (1973: 161) julga serem requisitos da crítica. Ao discorrer sobre seus critérios de avaliação, analisa as relações "de um sistema crítico com aqueles que o precederam". A autora sugere que um dos aspectos a ser valorizado na crítica é sua originalidade. Ela afirma que "a nova crítica deve fornecer informação nova”. Podemos depreender de sua análise a relação intrínseca existente entre críticas, aspecto que já apontamos anteriormente. Acrescentamos portanto que, ao estudarmos as críticas agrupadas nesta série, observamos a ausência dessa característica por ela apontada. As informações apresentadas são centradas no estilo de Jack Kerouac; no entanto, não excedem os comentários meramente descritivos, ora da obra, ora de seu autor. 
Jenny (1979: 5) analisa a inserção que todo texto exerce sobre aqueles que o antecederam, iniciando uma "relação de realização, de transformação ou de transgressão". Todavia, determina que entre crítica e intertextualidade há um texto originário que opera essas relações:

... a intertextualidade designa não uma soma confusa e misteriosa de influências, mas o trabalho de transformação e assimilação de vários textos, operado por um texto centralizador, que detém o comando do sentido. (Jenny, 1979: 14)

Empregamos esse pressuposto no presente estudo para entendermos a constituição dessa relação essencial entre textos críticos com o texto criticado. Admitimos a visivel relação estabelecida entre a crítica com a obra criticada que, conforme aponta Perrone-Moisés (op. cit.), constitui-se em relação intertextual elementar da crítica. No entanto, identificamos essa relação como sendo a condição única de comentário estabelecida pela crítica ao apresentar as traduções de Jack Kerouac.

\section{Análise das criticas de Viajante solitário, $O$ livro dos sonhos e Big Sur ${ }^{11}$}

Como pudemos observar, as resenhas sobre On the road: pé na estrada celebraram a publicação da obra no Brasil. A respeito das resenhas de Os subterrâneos, pudemos observar o destaque dado à narrativa de Kerouac. Embora com repetição de informações, foram traçados elogios à linguagem direta e rápida do escritor. Observamos uma tônica diferente permear o conjunto das resenhas sobre os três últimos romances traduzidos e publicados no Brasil: Viajante solitário, O Livro dos sonhos e Big Sur. Os elogios à narrativa, salientados nas criticas anteriores, adquirem novo tom.

\footnotetext{
11 Optamos por incluir a análise das críticas desses três livros em uma mesma série em razão da pequena quantidade de resenhas recolhidas e pelo motivo de algumas delas apresentarem Viajante solitário e O livro dos sonhos na mesma resenha.
} 
Almeida (1985), comentando O livro dos sonhos e O viajante solitário, ironiza o termo "modernidade" no Brasil, pois identifica as traduções da literatura beat apenas como uma "exumação". Com essa afirmação, observamos repetir-se a idéia de revival mencionada inicialmente. Em virtude do marcado caráter autobiográfico da obra de Kerouac, sugere que basta ler um só livro do autor. ${ }^{12}$ Destacamos que comentário semelhante é elaborado por Moura Júnior (1989), que incluiremos a seguir. Sem desenvolver argumentos para sua classificação, chama a prosa espontânea de Kerouac de uma "conversa fiada de bêbado".

Nessa mesma linha de pensamento, Campello (1985a), ao comentar a publicação de $O$ livro dos sonhos, declara não ter visto na obra de Kerouac aspectos relevantes que possam ser denominados literários. Afirma que a obra não apresenta elementos que possam atrair o leitor, tais como "estrutura, coerência e uma linha diretiva mínima". A exemplo da áspera denominação atribuída à prosa de Kerouac na resenha de Almeida (op. cit.), esta utiliza os mesmos artifícios, ao classificá-la de "pobre e completamente ineficaz do ponto de vista literário", cujo texto apresentaria uma "bobajada artificial".

Resgatamos o exemplo de intertexto presente nos artigos de Nobre (1985), Campello (1985b), no qual ela comenta a publicação de Big Sur, e de Moura Júnior (op. cit.), ao analisar a obra de Ann Charters, Kerouac: uma biografia. Nobre afirma que Kerouac "é uma criança que esqueceu de crescer". Acredita que Kerouac é muito mais lembrado como "personalidade" que como escritor. Esse crítico retoma, ainda, as classificações utilizadas por outros críticos, julgando ser Big Sur, uma "sucessão de equívocos". Sua leitura para justificar as traduções dos textos beat no Brasil recupera a polêmica suscitada sobre a criação de um "modismo" que, segundo o resenhista, é fruto de um país onde prosa e poesia estavam estagnadas. Em Campello, a mesma característica mencionada por Nobre é atribuída ao escritor - "ingenuidade infantil”. Esse julgamento, de acordo com o artigo,

\footnotetext{
12 Quase todos os romances de Kerouac trazem a mesma personagem, com outro nome, mas sempre uma crônica autobiográfica de uma fase de sua vida transformada em narrativa de ficção.
} 
deve-se ao fato das obras de Kerouac descreverem fases de sua vida e acontecimentos que, embora "corriqueiros", segundo Campello, Kerouac vê como "inusitados". Após citar alguns exemplos desses acontecimentos na obra, classifica Kerouac como escritor sem talento. Ao se referir à "prosa espontânea", presente em James Joyce e Virginia Woolf, deprecia a narrativa de Kerouac, afirmando ser seu estilo "fragmentado". Finalmente, Moura Júnior, comentando a obra de Charters, recorre a comparação semelhante ao afirmar que viu um antecedente célebre de Kerouac - Peter Pan.

Alvarez (1985), em sua análise sobre O viajante solitário, analisa o relançamento dos escritores beat como "boa aposta comercial". Nobre (op. cit.), como acabamos de ver, também vai por essa mesma linha. Diferentemente dos artigos que comparam Kerouac a nomes importantes da literatura norte-americana, Alvarez acredita que não há elementos presentes na obra de Kerouac para proceder a tal comparação. Fato que se justifica quando profetiza: "a posteridade pode tardar e ser cruel, mas não falha".

Conforme salientamos acima, a tônica presente nessa série difere radicalmente dos comentários sobre as duas primeiras obras traduzidas. O único artigo que busca elogiar Kerouac traz em seu título referência ao estilo do escritor: "O espontâneo Kerouac" (Valle, 1985). Nos demais, encontramos um caráter depreciativo: "A prosa de Kerouac, uma interminável conversa fiada" (Almeida, 1985), "Um sonho é como outro sonho. Mas a leitura vira pesadelo" (Campello, 1985a), "Quando o menor espirro beat vale ainda mais que ouro puro" (Alvarez, 1985), "Nada mais que uma sucessão de equívocos" (Nobre, 1985) e "Ingenuidades à beira da estrada: um beat admira o próprio umbigo" (Campello, 1985b).

\section{Considerações finais}

De forma geral, conforme nos propusemos observar, acreditamos que a análise das resenhas citadas nessa pesquisa nos possibilitou mapear a recepção crítica da obra de Jack Kerouac, 
no Brasil. O estudo de como essas resenhas se apresentaram ajudou a demonstrar como a avaliação da sua obra foi oscilante. A partir do momento inicial da recepção até às últimas resenhas aqui comentadas, pudemos notar que o comportamento eufórico inicial da crítica evoluiu para uma desvalorização progressiva da obra de Jack Kerouac.

Em muitas das resenhas, a abordagem consiste em referências claras às informações biográficas ou comportamentais do autor. Por meio do aspecto intertextual nelas apresentado, buscamos explicitar o interesse descrito no início desse trabalho, acerca da construção de textos a partir da relação, adição e transformação de outros textos. Essa seqüência de citações e "diálogos" entre as críticas constitui uma "montagem", uma "colagem" de vários artigos e opiniões. Acreditamos que, ao estudar as leituras dos críticos, detectamos, na maioria delas, ausência de leitura mais comprometida com a obra toda de Jack Kerouac, aspecto que avaliamos tornar a abordagem crítica periférica e limitada.

A partir do ensaio de Perrone-Moisés (1973), observamos nas resenhas, de maneira preponderante, o não-cumprimento de algumas condições postuladas como necessárias para a eficácia da crítica. A primeira diz respeito à descrição das obras apresentadas. Percebemos a definição do objeto (obra) de uma maneira não-precisa e limitada, com raros comentários pontuais, transformando o texto analisado em um objeto simbólico, representativo de uma geração ou ideologia. As escassas informações originais sobre as obras nos levam a outra condição estabelecida por Perrone-Moisés - a introdução de um novo elemento a cada crítica - que também apontamos como sendo momento incomum nas críticas aqui agrupadas. Finalmente, outra exigência não preenchida, trata-se de comunicar a "pluralidade" da obra, desacreditando apresentar verdade única.

Salientamos novamente o atraso ocorrido nas traduções no Brasil das obras aqui relacionadas. O interesse inicial por parte do tradutor Eduardo Bueno, após percorrer o mesmo trecho descrito em On the road, foi transformado pelos críticos, à época da tradução, em "jogada de marketing". Perdeu-se muito tempo em torno da discussão para classificar o início das traduções dos escritores beat no Brasil como modismo ou não; se o 
texto de Kerouac possuía caráter ficcional ou não. On the road, por exemplo, parece ter sido responsável por tornar Jack Kerouac um autor de narrativas "aventureiras". Ressaltamos que as diversas indagações sobre o valor literário de Kerouac aplacaram uma leitura mais pontual, cuja apreciação sobre sua obra pudesse ocorrer com maior rigor e detalhamento.

Acreditamos que a tentativa de buscar uma justificativa para as publicações das traduções das obras de Jack Kerouac no Brasil, por meio de "diálogos" exaustivos, com excessiva repetição de informações biográficas e comportamentais, permitiu que o tratamento dado a Kerouac como ícone da geração beatse consolidasse, provocando uma ruptura da sua recepção como autor. Acreditamos ser sugestivo o fato de nenhuma outra obra de Kerouac ter sido traduzida no Brasil após Big Sur, considerando ao menos a década que se seguiu aos anos 1980 .

Concluímos que o interesse pelo estilo da linguagem de Kerouac parece não ter excedido à atenção de poucos críticos, poetas e escritores. Retomamos que, por apresentar um texto com marcada característica prosódica, aspecto considerado complexo e que, como citado anteriormente, foi apontado como um dos legados de Kerouac para a literatura, leva-nos a acreditar, portanto, na necessidade do despontar de um estudo onde esse atributo fosse analisado com maior profundidade.

Finalmente, julgamos que o trabalho do tradutor, a despeito de algumas considerações sugeridas por meio das resenhas, tais como ser oficio subestimado (e portanto, mal remunerado), é tarefa desafiadora e minuciosa, a qual estabelece forte relação entre leitor e obra traduzida. Afinal, sabemos que a tradução também determina o valor literário de uma obra.

\section{Referências bibliográficas}

A PROSA do futuro em Os subterrâneos, de Kerouac. Correio da Bahia, Salvador, 22 out. 1984.

ABREU, C. F. Pé na estrada. Gallery Around, São Paulo, mar. 1984.

ALMEIDA, M. M. A prosa de Kerouac, uma interminável conversa fiada. Jornal da Tarde, São Paulo, 4 fev. 1985. Livros/Crítica. 
ALVAREZ, A. Quando o menor espirro beat vale ainda mais que ouro puro. O Globo, Rio de Janeiro, 3 mar. 1985. Segundo Caderno.

ASSUNÇÃO, A. Pé na estrada. Folha de Londrina, Londrina, 7 dez. 1984. Caderno 2.

BIONDO, S. Na alma dos personagens e do cenário, um documento de época. O Globo, Rio de Janeiro, 16 set. 1984.

CALINESCU, M. Rereading. New Haven: Yale UP, 1993.

CAMPELLO, M. Um sonho é como outro sonho. Mas a leitura vira pesadelo. O Globo, Rio de Janeiro, 10 fev. 1985a.

. Ingenuidades à beira da estrada: um beat admira o próprio umbigo. O Globo, Rio de Janeiro, 18 ago. 1985b.

CICCACIO, A. M. Com 27 anos de atraso, chega ao Brasil o credo do movimento beat. O Estado de S. Paulo, São Paulo, 26 fev. 1984.

FERRAZ, G. G. Os subterrâneos. ISTOÉ, São Paulo, 29 ago. 1984.

FIORIN, J. L. Polifonia textual e discursiva. In: BARROS, D. L. P. \& FIORIN, J. L., (Orgs.). Dialogismo, polifonia, intertextualidade: em torno de Mikhail Bakhtin. São Paulo: Editora da Universidade de São Paulo, 1994.

FRÓES, L. As emoções de Jack, o santo maluco. Jornal do Brasil, Rio de Janeiro, 8 set. 1984.

GONZALEZ, H. O anjo decaído. ISTOÉ, São Paulo, p. 72, 15 dez. 1984. ISMAEL, J. C. Celebrando a inocência perdida. O Estado de S. Paulo, São Paulo, 25 mar. 1984. Caderno Cultura.

JENNY, L. A estratégia da forma. In: . (Org.). Intertextualidades. Coim-

bra: Ed. Almedina, 1979. Título original: Poétique - n. 27, p. 5-49.

JUNQUEIRA, I. O moderno clássico da beat generation. O Globo, Rio de Janeiro, 18 mar. 1984.

MENEZES, C. Quase 30 anos depois, enfim em português, On the road. O Globo, Rio de Janeiro, 24 fev. 1984. Livros.

MOURA JÚNIOR, J. O escritor beat Jack Kerouac era infantil. Folha de S. Paulo, São Paulo, 21 out. 1989.

NAS LIVRARIAS, os textos que saem no ritmo dos corações. O Globo, Rio de Janeiro, 14 set. 1984.

NO RITMO do coração: nervoso e incandescente, chega ao Brasil o clássico da geração beatnik - On the road, de Jack Kerouac. Veja, São Paulo, p. 99-100, 22 fev. 1984.

O GRANDE clássico da geração beat (título atribuido pelo organizador/ autor da dissertação). Jornal do Unibanco, São Paulo, abr. 1984. 
O MELHOR da literatura beat. Jornal Real, São Paulo, set. 1984.

ON THE ROAD, de Kerouac: a bíblia beat chega ao Brasil. Correio da Bahia, Salvador, 23 abr. 1984.

ON THE ROAD: o relato de viagem da geração beat. Pioneiro, Caxias do Sul, 14 abr. 1984.

PAIVA, M. R. Um vagabundo descobre a América. Veja, São Paulo, p. 100, 22 fev. 1984.

PERRONE-MOISÉS, L. Falência da crítica. São Paulo: Perspectiva, 1973. . Texto, crítica, escritura. São Paulo: Ática, 1993.

PINTO, J. N. Pé na estrada. Jornal do Brasil, Rio de Janeiro, 10 mar. 1984.

QUERINO NETO, A. Na estrada, quase 30 anos depois. [s.n.]. Sorocaba, 10 mar. 1984. Reportagem/Leitura.

ROCHA, J. O. Os subterrâneos. Tribuna da Bahia, Salvador, 8 set. 1984. UCHA, D. P. On the road: sair é viver, ficar é apodrecer. Zero Hora, Porto Alegre, 28 mar. 1984. $2^{\circ}$ Caderno.

VALLE, D. O espontâneo Kerouac. O Estado de S. Paulo, São Paulo, 21 abr. 1985. Cultura.

WILLER, C. Apresentação. In: KEROUAC, J. Os subterrâneos. Tradução de Paulo Henriques Britto. São Paulo: Brasiliense, 1984. p. 7-14. 